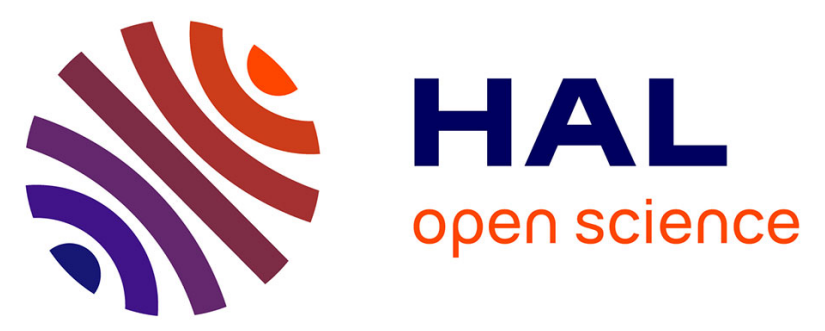

\title{
A long-term dynamic model for predicting the concentration of semivolatile organic compounds in indoor environments: application to phthalates
}

Wenjuan Wei, Olivier Ramalho, Corinne Mandin

\section{- To cite this version:}

Wenjuan Wei, Olivier Ramalho, Corinne Mandin. A long-term dynamic model for predicting the concentration of semivolatile organic compounds in indoor environments: application to phthalates. Building and Environment, 2019, 148, pp.11 - 19. 10.1016/j.buildenv.2018.10.044 . hal-02363642

HAL Id: hal-02363642

https://hal-cstb.archives-ouvertes.fr/hal-02363642

Submitted on 14 Nov 2019

HAL is a multi-disciplinary open access archive for the deposit and dissemination of scientific research documents, whether they are published or not. The documents may come from teaching and research institutions in France or abroad, or from public or private research centers.
L'archive ouverte pluridisciplinaire $\mathbf{H A L}$, est destinée au dépôt et à la diffusion de documents scientifiques de niveau recherche, publiés ou non, émanant des établissements d'enseignement et de recherche français ou étrangers, des laboratoires publics ou privés. 
Article published in Building and Environment, 148, January 2019, p. 11-19

[https://doi.org/10.1016/j.buildenv.2018.10.044]

\title{
A long-term dynamic model for predicting the concentration of semivolatile organic compounds in indoor environments: application to phthalates
}

\begin{abstract}
Wenjuan Wei", Olivier Ramalho, Corinne Mandin
University of Paris-Est, Scientific and Technical Center for Building (CSTB), Health and Comfort Department, French Indoor Air Quality Observatory (OQAI), 84 Avenue Jean Jaurès, Champs sur Marne, 77447 Marne la Vallée Cedex 2, France

*Corresponding author: Centre Scientifique et Technique du Bâtiment (CSTB), Direction SantéConfort - Observatoire de la Qualité de l'Air Intérieur (OQAI), 84 Avenue Jean Jaurès, Champs sur Marne, 77447 Marne la Vallée Cedex 2, France. Tel.: +331 6468 8457; Fax: +331 64688823. E-mail address: Wenjuan.WEI@ cstb.fr
\end{abstract}




\section{ABSTRACT}

Semivolatile organic compounds (SVOCs) in indoor environments can partition into the gas phase, airborne particles, and settled dust and onto available surfaces. A long-term dynamic model was developed to predict the hourly concentrations of SVOCs over a year in the gas phase, airborne particles, and settled dust and on each sink surface. The model takes into account mass transfer mechanisms, the reactivity of SVOCs with oxidants indoors, and the influence of four indoor environmental factors (the air temperature, relative humidity, concentration of indoor airborne particles, and air exchange rate) on the mass transfer parameters. The model was validated for DEHP (di-2-ethylhexyl phthalate) and BBzP (butyl benzyl phthalate) by comparing the predicted concentrations in all the phases with the measured concentrations obtained in an environmental chamber and a test house. The model was then used to predict the hourly averaged concentration of $\mathrm{BBzP}$ in all the phases under real environmental conditions over a year. More than $52 \%$ of the variance in the $\mathrm{BBzP}$ concentration was found to be associated with the covariance of the environmental factors. The air exchange rate contributed to $16 \%$ of the variance in the concentration. In addition, the indoor air temperature and relative humidity contributed $9 \%$ of the variance in the gas-phase concentration of $\mathrm{BBzP}$ and $7 \%$ of the variance in the settled dust concentration of BBzP. The variance in the concentration of the total suspended particles contributed $10 \%$ of the variance in the $\mathrm{BBzP}$ concentration on the walls and windows.

\section{KEYWORDS}

SVOC; phthalate; emission; partition; building material; indoor air quality 


\section{INTRODUCTION}

Semivolatile organic compounds (SVOCs), such as phthalates, flame retardants, pesticides, and polycyclic aromatic hydrocarbons, may originate from both indoor and outdoor sources and partition in indoor environments among the gas phase, airborne particles, settled dust, and available surfaces [1]. Consequently, occupants can be exposed indoors to SVOCs through multiple pathways such as inhalation [2], dermal uptake [3], and ingestion of settled dust [4]. To evaluate the health risk associated with indoor exposure to SVOCs, the SVOC concentrations need to be either measured in all the phases or estimated by modeling.

Several studies have been carried out to address the mass transfer mechanism of SVOCs in indoor environments [5-8], and fugacity-based models have been developed to predict indoor SVOC concentrations [9-11]. The first dynamic model was developed to predict the emission of phthalates from a piece of vinyl flooring into the gas phase and the mass transfer of phthalates between the gas phase and airborne particles in a single room [12]. The phthalate concentrations in both the gas phase and airborne particles were predicted. The settled dust and several sink surfaces, e.g., window and human skin, were then added to the model, and the model was extended from a single room to two adjacent rooms [13]. The SVOC concentrations in the gas phase, airborne particles, settled dust, and on each sink surface were predicted. Later, the model was improved by considering the deposition of airborne particles, the resuspension of settled dust [14,15], and the reactivity of SVOCs with hydroxyl radicals, nitrate radicals, and ozone [16]. For the prediction of SVOC concentrations for a large dataset of buildings, a probabilistic approach based on Monte Carlo simulation was developed to predict the distribution of the SVOC concentrations under equilibrium conditions [17]. 
Environmental factors, e.g., indoor air temperature, relative humidity, the concentration of airborne particles, and the air exchange rate, have a significant influence on mass transfer parameters such as mass transfer coefficients and partition coefficients [18]. To use modeling approaches with real environmental conditions, the impact of the environmental factors on the mass transfer parameters needs to be integrated into the equations of the models and quantified at each time step of the calculation.

Therefore, the objective of this study is to develop a dynamic model to predict the concentration of SVOCs in real indoor environments over long periods. To reach this objective, three aspects should be considered while developing a model: (1) the model should include the emission of SVOCs from multiple surface sources and the sorption of SVOCs onto multiple sink materials; (2) the model should include the mass transfer mechanisms of SVOCs, the deposition and resuspension of particles, and the reactivity of SVOCs; and (3) the model should address the impact of environmental factors on the mass transfer parameters and concentrations of SVOCs at each time step of the calculation.

\section{MATERIAL AND METHODS}

\subsection{Development of the model}

To predict SVOC concentrations in indoor environments, the following mechanisms were considered in the model (Fig. 1): (1) the continuous emission of SVOCs from indoor surfaces to the gas phase; (2) the mass transfer of SVOCs among the gas phase, airborne particles, settled dust, and sink surfaces; (3) the transport of SVOCs between indoor and outdoor environments in the gas 
phase, airborne particles, and settled dust; (4) the gas- and particle-phase reaction of SVOCs with oxidants indoors; and (5) the deposition of airborne particles onto floor dust and other surfaces (e.g., furniture) and the resuspension of the dust into the air. To fully address the mass transfer processes of SVOCs in a room for a robust prediction of SVOC concentrations, the model is currently based on a single-room environment, and it will be extended to a multiroom environment in the future.

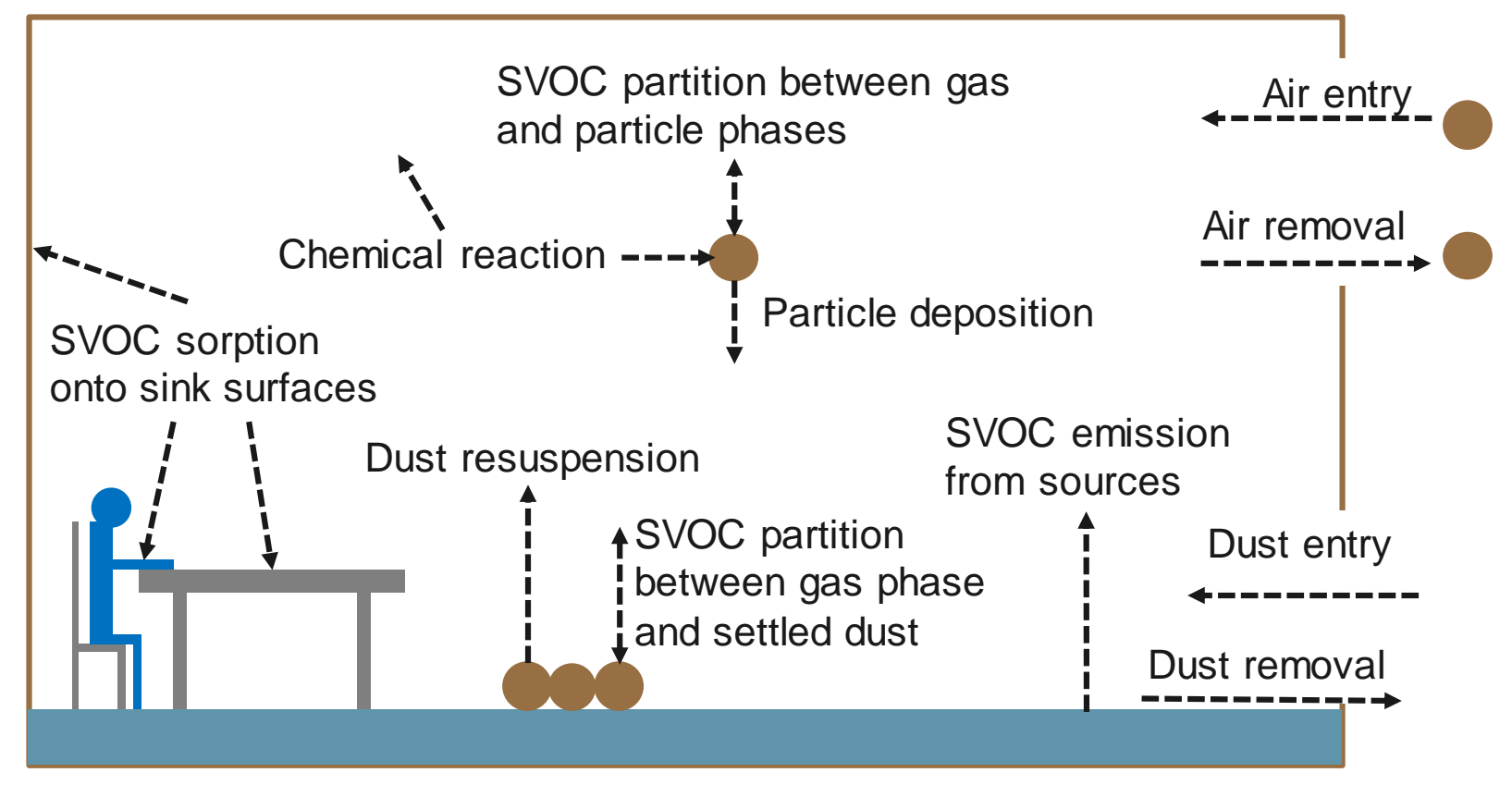

Fig. 1. Schematic of the model.

The model assumes that (1) the indoor air is well mixed; (2) the SVOC mass transfer efficiency between indoor and outdoor environments equals one; (3) SVOC indoor sources are surfaces (e.g., building materials and coatings, decoration products, furniture, and office equipment) that emit continuously and infinitely on the time scale of the prediction; and (4) SVOC indoor sink materials 
are impermeable. Thus SVOCs are absorbed on the surface of the materials. The gas-phase concentration of a compound is described by

$$
\begin{gathered}
\frac{\mathrm{d} C_{\mathrm{g}}}{\mathrm{d} t} V_{\mathrm{a}}=\sum_{i} h_{\mathrm{me}, i} A_{\mathrm{e}, i}\left(y_{0, i}-C_{\mathrm{g}}\right)-h_{\mathrm{mp}} A_{\mathrm{p}}\left(C_{\mathrm{g}}-\frac{C_{\mathrm{p}}}{T S P \times K_{\mathrm{p}}}\right)-h_{\mathrm{md}} A_{\mathrm{d}}\left(C_{\mathrm{g}}-\frac{C_{\mathrm{d}}}{K_{\mathrm{d}}}\right) \\
-\sum_{j} h_{\mathrm{ms}, j} A_{\mathrm{s}, j}\left(C_{\mathrm{g}}-\frac{C_{\mathrm{s}, j}}{K_{\mathrm{s}, j}}\right)+Q\left(C_{\mathrm{gin}}-C_{\mathrm{g}}\right)-\sum_{x} k_{1 \mathrm{~g}, x} C_{\mathrm{g}} V_{\mathrm{a}}
\end{gathered}
$$

where $C_{\mathrm{g}}\left(\mu \mathrm{g} / \mathrm{m}^{3}\right), C_{\mathrm{p}}\left(\mu \mathrm{g} / \mathrm{m}^{3}\right), C_{\mathrm{d}}(\mu \mathrm{g} / \mathrm{g})$, and $C_{\mathrm{s}}\left(\mu \mathrm{g} / \mathrm{m}^{2}\right)$ are the concentrations of the compound in the gas-phase, airborne particles, settled dust on the floor, and sink surfaces in the room, respectively; $t(\mathrm{~h})$ is time, $V_{\mathrm{a}}\left(\mathrm{m}^{3}\right)$ is the volume of the room; $h_{\mathrm{me}}, h_{\mathrm{mp}}, h_{\mathrm{md}}$, and $h_{\mathrm{ms}}(\mathrm{m} / \mathrm{h})$ are the mass transfer coefficients in the boundary layer of the source surfaces, airborne particles, settled dust, and sink surfaces, respectively; $A_{\mathrm{e}}, A_{\mathrm{p}}, A_{\mathrm{d}}$, and $A_{\mathrm{s}}\left(\mathrm{m}^{2}\right)$ are the areas of the source surfaces, airborne particles, settled dust on the floor, and sink surfaces, respectively; $y_{0}\left(\mu \mathrm{g} / \mathrm{m}^{3}\right)$ is the gasphase concentration adjacent to the source surface; and TSP $\left(\mu \mathrm{g} / \mathrm{m}^{3}\right)$ is the concentration of the total suspended particles in indoor air. TSP is related to indoor/outdoor particle transport, particle dynamics indoors, and indoor particle emission. Indoor particle emission is influenced by human activities such as cooking and cleaning. No model can fully address the indoor particle concentration unless a scenario is defined with scheduled activity of particle sources and changes in window openings. Therefore, instead of calculating the indoor particle concentration using a particle mass balance equation under a particular activity scenario, the current model requires the indoor particle concentration as an input. This input can be constant or time dependent and can be measured or predicted from other particle transport models. $K_{\mathrm{p}}\left(\mathrm{m}^{3} / \mu \mathrm{g}\right), K_{\mathrm{d}}\left(\mathrm{m}^{3} / \mathrm{g}\right)$, and $K_{\mathrm{s}}(\mathrm{m})$ are the particle/gas, dust/gas, and sink/gas partition coefficients, respectively; $C_{\text {gin }}\left(\mu \mathrm{g} / \mathrm{m}^{3}\right)$ is the outdoor gas-phase concentration of the compound with a transfer efficiency assumed to be equal 
to one; $Q\left(\mathrm{~m}^{3} / \mathrm{h}\right)$ is the air flow rate; and $k_{1 \mathrm{~g}}\left(\mathrm{~h}^{-1}\right)$ is the pseudo-first-order reaction rate constant in the gas phase. The model refers to the emission of SVOCs from multiple sources, the sorption of SVOCs onto multiple sink surfaces, and the reaction of SVOCs with multiple oxidants. The subscripts, $i, j$, and $x$, represent the multiple sources, sinks, and oxidants (e.g., hydroxyl radicals, nitrate radicals, and ozone). Eq. (1) considers the continuous emission of a compound from source surfaces, while the emission from intermittent sources is not considered in the current model. The sink surfaces are assumed to be impermeable $[6,19]$. Therefore, SVOCs can form an organic film on the sink surface, and the diffusion of SVOCs through the material is neglected. Some recent studies have observed the mass transfer of SVOCs between source materials and settled dust in direct contact [20,21]. However, this process is not taken into account in the current model.

The average SVOC concentration in the airborne particles of all sizes is described by

$$
\begin{gathered}
\frac{\mathrm{d} C_{\mathrm{p}}}{\mathrm{d} t} V_{\mathrm{a}}=h_{\mathrm{mp}} A_{\mathrm{p}}\left(C_{\mathrm{g}}-\frac{C_{\mathrm{p}}}{T S P \times K_{\mathrm{p}}}\right)-C_{\mathrm{p}} v_{\mathrm{dep}}\left(A_{\mathrm{ddep}}+\sum_{j} A_{\mathrm{sdep}, j}\right)+R_{\mathrm{sus}}\left(C_{\mathrm{d}} \rho_{\mathrm{d}} V_{\mathrm{dsus}}\right. \\
\left.+\sum_{j} C_{\mathrm{d}, j} A_{\mathrm{ssus}, j}\right)+Q\left(C_{\mathrm{pin}}-C_{\mathrm{p}}\right)-\sum_{x} k_{1 \mathrm{p}, x} C_{\mathrm{p}} V_{\mathrm{a}}
\end{gathered}
$$

where $v_{\text {dep }}(\mathrm{m} / \mathrm{h})$ is the deposition velocity of airborne particles of all sizes; $A_{\text {ddep }}$ and $A_{\text {sdep }}\left(\mathrm{m}^{2}\right)$ are the deposition areas of the floor dust and other surfaces; and $R_{\text {sus }}\left(\mathrm{h}^{-1}\right)$ is the resuspension rate of the deposited particles of all sizes. $v_{\text {dep }}$ is associated with the type of surface and particle size distribution. However, there is insufficient information in the literature addressing the sizedependent particle deposition velocity for each type of indoor surface. Therefore, the current model uses an identical value for all surfaces for practical reasons. To include particle size effects in the model, the size distribution of indoor airborne particles and its changes over time need to be defined. Studies on the daily change of the indoor particle size distribution are rare. Therefore, the 
current model focuses on indoor $\mathrm{PM}_{10}$ for simplicity. The $v_{\text {dep }}(1.1 \mathrm{~m} / \mathrm{h})$ and $R_{\text {sus }}\left(2.4 \times 10^{-5} \mathrm{~h}^{-1}\right)$ values were retrieved from the literature $[14,15]$. The present model separates the floor dust from dust settled on other surfaces. Due to the large number of indoor surfaces, it is not feasible to model the dust concentration of SVOCs on each surface. In a normally cleaned room, a very thin layer of dust may exist on a surface. The dust concentration is associated with the surface concentration of SVOCs. Therefore, the present model assumes that the dust concentration on a sink surface $\left(C_{\mathrm{d}, j}\right)$ is equal to the surface concentration $\left(C_{\mathrm{s}, j}\right)$ for simplicity. $\rho_{\mathrm{d}}\left(\mathrm{g} / \mathrm{m}^{3}\right)$ is the density of the settled dust, and $V_{\mathrm{dsus}}\left(\mathrm{m}^{3}\right)$ is the volume of the floor dust that may resuspend. Dust mass loading is assumed to be constant. $A_{\text {ssus }}\left(\mathrm{m}^{2}\right)$ is the area of the other surfaces where deposited particles may resuspend. Since deposited particles on a surface can also resuspend, $A_{\text {ssus }, j}$ is assumed to be equal to $A_{\text {sdep }, j} . C_{\text {pin }}\left(\mu \mathrm{g} / \mathrm{m}^{3}\right)$ is the outdoor particle-phase concentration of the compound with a transfer efficiency assumed to be equal to one, and $k_{1 \mathrm{p}}\left(\mathrm{h}^{-1}\right)$ is the pseudo-first-order reaction rate constant of the compound in the particle phase.

The average SVOC concentration in the floor settled dust of all sizes without taking into account possible SVOC mass transfer between the source flooring and dust in direct contact is described by

$$
\begin{gathered}
\frac{\mathrm{d} C_{\mathrm{d}}}{\mathrm{d} t} \rho_{\mathrm{d}} V_{\mathrm{d}}=h_{\mathrm{md}} A_{\mathrm{d}}\left(C_{\mathrm{g}}-\frac{C_{\mathrm{d}}}{K_{\mathrm{d}}}\right)+C_{\mathrm{p}} v_{\mathrm{dep}} A_{\mathrm{ddep}}-R_{\mathrm{sus}} C_{\mathrm{d}} \rho_{\mathrm{d}} V_{\mathrm{dsus}}-\sum_{x} k_{1 \mathrm{~d}, x} C_{\mathrm{d}} \rho_{\mathrm{d}} V_{\mathrm{d}} \\
+q_{\mathrm{din}} \rho_{\mathrm{din}} C_{\mathrm{din}}-q_{\mathrm{dout}} \rho_{\mathrm{d}} C_{\mathrm{d}}
\end{gathered}
$$

where $k_{1 \mathrm{~d}}\left(\mathrm{~h}^{-1}\right)$ is the pseudo-first-order reaction rate constant in the settled dust; $V_{\mathrm{d}}\left(\mathrm{m}^{3}\right)$ is the volume of the floor dust; $q_{\mathrm{din}}$ and $q_{\mathrm{dout}}\left(\mathrm{m}^{3} / \mathrm{h}\right)$ are the flow rates of the dust entering and leaving the room, respectively; $\rho_{\operatorname{din}}\left(\mathrm{g} / \mathrm{m}^{3}\right)$ is the density of the dust entering the room; and $C_{\mathrm{din}}(\mu \mathrm{g} / \mathrm{g})$ is the concentration of the compound in the dust coming from outdoors. Due to the difficulty in assessing 
it, the transport of settled dust between the indoor and outdoor environments was not considered in the present study. Therefore, the flow rates $\left(q_{\text {din }}\right.$ and $\left.q_{\text {dout }}\right)$ were assumed to be equal to zero, and the volume of the floor dust was assumed to be constant.

The concentration of the compound on a sink surface is described by

$$
\frac{\mathrm{d} C_{\mathrm{s}, j}}{\mathrm{~d} t} A_{\mathrm{s}, j}=h_{\mathrm{ms}, j} A_{\mathrm{s}, j}\left(C_{\mathrm{g}}-\frac{C_{\mathrm{s}, j}}{K_{\mathrm{s}, j}}\right)+C_{\mathrm{p}} v_{\mathrm{dep}} A_{\mathrm{sdep}, j}-R_{\mathrm{sus}} C_{\mathrm{s}, j} A_{\mathrm{ssus}, j}-\sum_{x} k_{1 \mathrm{~s}, x} C_{\mathrm{s}, j} A_{\mathrm{s}, j}
$$

where $k_{1 \mathrm{~s}}\left(\mathrm{~h}^{-1}\right)$ is the pseudo-first-order reaction rate constant on the surface.

The mass transfer parameters in the model were retrieved from measured values in the literature or estimated using equations developed in previous studies. Direct measurements of $y_{0}$ for phthalates have been carried out for various floorings [8,22] and mattresses [23]. For phosphorous and brominated flame retardants, the concentrations in indoor air were measured when computers and televisions were present in the room [24,25]. Information on SVOC emissions from other indoor sources is not available in the literature. The mass transfer coefficients [26,27], partition coefficients $[6,28]$ and reaction rate constants [16] can be calculated using methods developed in previous studies.

Eqs. $(1-4)$ can be transferred into a system of $m(m=j+3)$ linear equations using the finite difference method. To ensure the stability and convergence of the solution, the backward difference method was used in the model.

$$
\mathbf{A x}=\mathbf{b}
$$

where $\mathbf{A}$ is an $m \times m$ matrix, $\mathbf{x}$ is a column vector with $m$ concentrations $\left(C_{\mathrm{g}}, C_{\mathrm{p}}, C_{\mathrm{d}}\right.$, and $C_{\mathrm{s}}$ for each of the $j$ surfaces) and $\mathbf{b}$ is a column vector with $m$ entries. 


$$
\mathbf{A}=\left[\begin{array}{cccccc}
a_{11} & a_{12} & a_{13} & a_{14} & \cdots & a_{1 m} \\
a_{21} & a_{22} & a_{23} & a_{24} & \cdots & a_{2 m} \\
a_{31} & a_{32} & a_{33} & a_{34} & \cdots & a_{3 m} \\
a_{41} & a_{42} & a_{43} & a_{44} & \cdots & a_{4 m} \\
\vdots & \vdots & \vdots & \vdots & \ddots & \vdots \\
a_{m 1} & a_{m 2} & a_{m 3} & a_{m 4} & \cdots & a_{m m}
\end{array}\right], \mathbf{x}=\left[\begin{array}{c}
C_{\mathrm{g}} \\
C_{\mathrm{p}} \\
C_{\mathrm{d}} \\
C_{\mathrm{s}, 1} \\
\vdots \\
C_{\mathrm{s}, j}
\end{array}\right], \mathbf{b}=\left[\begin{array}{c}
b_{1} \\
b_{2} \\
b_{3} \\
b_{4} \\
\vdots \\
b_{\mathrm{m}}
\end{array}\right]
$$

The entries in matrix $\mathbf{A}$ and vector $\mathbf{b}$ are functions of (1) the geometry and air flow rate of the room, (2) the mass transfer parameters, (3) the surface of the source/sink materials, (4) the concentration of the total suspended particles, and (5) the density of settled dust. Detailed information on the entries of the matrix $\mathbf{A}$ and vector $\mathbf{b}$ is provided in the supporting information (SI). The values of model parameters are provided in Table S1 in the SI.

The indoor temperature $(T)$, relative humidity $(R H)$, air exchange rate $(A E R)$, and airborne particle concentration $(T S P)$ can influence the mass transfer parameters and concentrations of SVOCs (Fig. 2). The impacts of the four environmental factors are not negligible and have been quantitatively addressed elsewhere [18]. The impacts of $T, R H, A E R$, and TSP were addressed quantitatively in the calculation of the mass transfer parameters in the model, e.g., $y_{0}$, mass transfer coefficients, and partition coefficients, using equations presented in the literature [18]. For each time step, the environmental factors were assumed to affect the mass transfer parameters without delay.

The model was coded in C\# language using Visual Studio 2015 (Microsoft Visual Studio Community 2015, version 14.0, 2016 Microsoft Corporation). A user-friendly interface was designed for nonprofessionals for the modeling of indoor SVOC concentrations (Fig. S1 in the SI). The total calculation time was set to 365 days to address concentrations over a long period that included all the seasons. The time step was set to $1 \mathrm{~h}$ by default and should not be reduced, because the environmental factors were assumed to affect the mass transfer parameters immediately. For 
example, the temperature on the source surface changes with the air temperature at each time step and affects the emission without delay. These values can be changed to adapt to special needs. The input data to initiate the calculation of the model include (1) the geometry and air flow rate of the room, (2) the size of the source/sink materials, (3) the initial concentration of SVOCs in the room, and (4) the outdoor SVOC concentrations and indoor TSP concentration over the whole calculation period, when needed. The values of $T, R H, A E R, T S P, C_{\mathrm{gin}}, C_{\mathrm{pin}}$, and $C_{\mathrm{din}}$ are the input data at each time step. $C_{\text {gin }}, C_{\mathrm{pin}}$, and $C_{\mathrm{din}}$ are set to zero by default and are modifiable. The other parameters in the model, e.g., the partition coefficients, the mass transfer coefficients, and $y_{0}$, were calculated under the environmental conditions of the time step. Then, the entries in matrix $\mathbf{A}$ and vector $\mathbf{b}$ were calculated using the updated parameters. Finally, the updated system of linear equations was solved using Gaussian elimination to calculate the values of $C_{\mathrm{g}}, C_{\mathrm{p}}, C_{\mathrm{d}}$, and $C_{\mathrm{s}}$ at the time step.

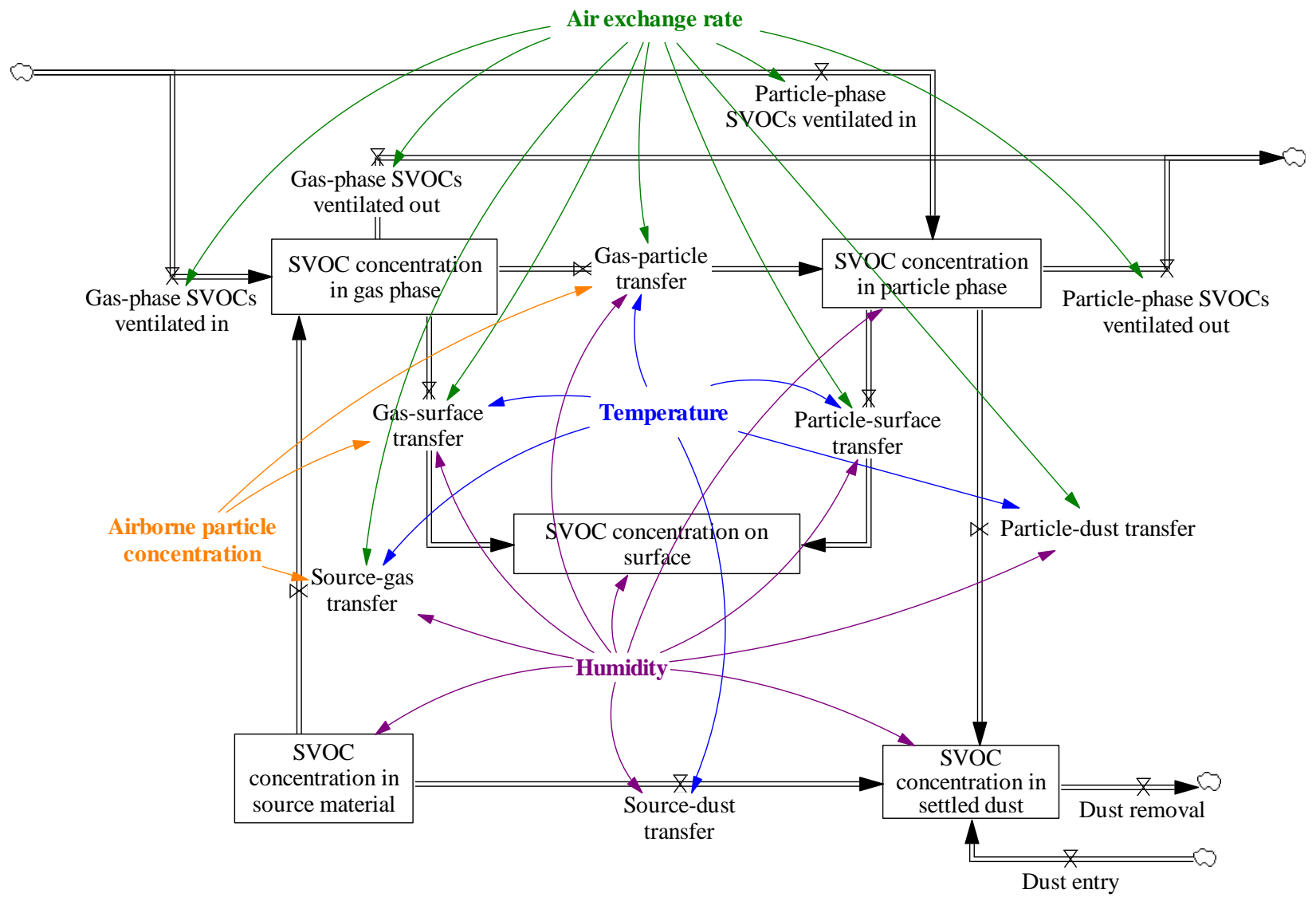


Fig. 2. Influence of environmental factors on the transport of SVOCs.

\subsection{Validation of the model}

Three predictions were performed to validate the model and to perform long-term dynamic predictions under real environmental conditions.

First, a validation of the model was carried out for di-2-ethylhexyl phthalate (DEHP) in a 2-L sandwich-like environmental chamber [22]. DEHP was emitted from a piece of vinyl flooring inside the chamber without the presence of airborne particles or settled dust. DEHP was measured in the chamber gas phase and was also absorbed on the surface of the chamber. All the environmental conditions remained constant during the duration of the experiment. The parameters for the model prediction (geometric parameters of the environmental chamber and the source material, source emission parameters, mass transfer coefficients, and partition coefficients) were retrieved from the measurement study [22], and the predicted hourly average concentrations were compared with the measured values.

Second, a validation of the model was performed for butyl benzyl phthalate (BBzP) measured in a $250-\mathrm{m}^{3}$ test house [29]. BBzP was emitted from the flooring of the test house. BBzP was measured in both the gas and airborne particles in the indoor air, settled dust, and on the walls (measured on wooden surfaces representing walls, ceilings and furniture) and windows of the house. The environmental factors $(T, R H$, and $A E R)$ were changed 4 times over a period of less than 200 days in total. The TSP remained constant $\left(4.0 \pm 3.8 \mu \mathrm{g} / \mathrm{m}^{3}\right)$ over the period of study. The parameters for the model prediction (geometric parameters of the test house and the source 
material, source emission parameters, mass transfer coefficients, partition coefficients, and environmental parameters of the test house) were retrieved from a measurement study [29], and the predicted hourly average concentrations were compared with the measured values.

\subsection{Application of the model: a case study}

The model was used to predict the BBzP concentrations under real indoor environmental conditions. Indoor temperature, RH, AER, and $\mathrm{PM}_{10}$ concentration were measured over a year (January 1-December 31, 2014) during a French study in a mechanically ventilated office [30,31] and used in the test house experiment. The hourly average values of the environmental parameters in the office were the entry data for the model (Figs. S2-S5 in the SI). The PM 10 concentration was used as the estimate of TSP. The hourly average AER was estimated from $\mathrm{CO}_{2}$ monitoring during the decay periods according to the method developed by Ramalho et al. [32]. The other geometry and material emission parameters were those from the abovementioned test house. The hourly average concentrations of BBzP over a year were predicted considering two cases. For the first case, the initial BBzP concentrations in all the phases were assumed to be zero. This case corresponded to the prediction in a newly built room. The dynamic concentrations were calculated when the hourly average values of the environmental factors were used. In addition, the steadystate concentrations were calculated with the yearly-average values of the environmental factors. For the second case, the initial BBzP concentration in all the phases was assumed to have reached the steady state that had been determined during the calculation of the first case. This case corresponded to a prediction in an existing room, and the hourly average concentrations were calculated for a period of a year. The contribution of each environmental factor to the variance in the $\mathrm{BBzP}$ concentration in each phase was estimated using the following equation. 


$$
\begin{aligned}
\left.\operatorname{Var}\left(C_{m}\right)\right|_{\text {Total }} & =\left.\operatorname{Var}\left(C_{m}\right)\right|_{\operatorname{Var}(T)}+\left.\operatorname{Var}\left(C_{m}\right)\right|_{\operatorname{Var}(R H)}+\left.\operatorname{Var}\left(C_{m}\right)\right|_{\operatorname{Var}(P M 10)} \\
& +\left.\operatorname{Var}\left(C_{m}\right)\right|_{\operatorname{Var}(A E R)} \pm\left.\operatorname{Var}\left(C_{m}\right)\right|_{\operatorname{Cov}(T, R H, P M 10, A E R)}
\end{aligned}
$$

where $\left.\operatorname{Var}\left(C_{m}\right)\right|_{\operatorname{Var}(T, R H, P M 10, A E R)}$ is the variance in the SVOC concentration (phase $m$ ); $\left.\operatorname{Var}\left(C_{m}\right)\right|_{\operatorname{Var}(T)},\left.\operatorname{Var}\left(C_{m}\right)\right|_{\operatorname{Var}(R H)},\left.\operatorname{Var}\left(C_{m}\right)\right|_{\operatorname{Var}(P M 10)}$, and $\left.\operatorname{Var}\left(C_{m}\right)\right|_{\operatorname{Var}(A E R)}$ are the variances in the SVOC concentration (phase $m$ ) due to the variance in the $T, R H, \mathrm{PM}_{10}$ concentration, and $A E R$, respectively; and $\left.\operatorname{Var}\left(C_{m}\right)\right|_{\operatorname{Cov}(T, R H, P M 10, A E R)}$ is the variance in the SVOC concentration (phase $m$ ) due to the covariance of all four environmental factors.

\section{RESULTS AND DISCUSSION}

\subsection{Validation of the model}

The predicted DEHP concentrations in both the gas phase and on the surface of the sandwich-like chamber were compared with the measured values (Fig. 3). Since the environmental factors remained constant, the DEHP concentrations $\left(C_{\mathrm{g}}\right.$ and $\left.C_{\mathrm{s}}\right)$ increased until they reached their steadystate values. Student's $t$-tests were performed to test the significance of the difference between the measured and predicted $C_{\mathrm{g}}$ and $C_{\mathrm{s}}$ values. The p-values $\left(0.65\right.$ for $C_{\mathrm{g}}$ and 0.32 for $\left.C_{\mathrm{s}}\right)$ are both higher than 0.05, which indicates that the differences between the measured and predicted concentrations are not significant.

The predicted BBzP concentrations in the test house were compared with the measured values. The profile of the concentrations in the air (the sum of $C_{\mathrm{g}}$ and $C_{\mathrm{p}}$ ) and the average concentrations over the measurement period in the settled dust, on the walls (on wooden surfaces, representing walls, ceilings and furniture), and on the windows are shown in Fig. 4. Since the environmental 
factors were changed only 4 times over a period of less than 200 days, the concentrations in the air could reach the steady state between two changes of the environmental factors. The p-value of the Student's $t$-test of the measured and predicted concentrations of BBzP in air is 0.62 , suggesting that the differences between the measured and predicted values are not significant.

(a)

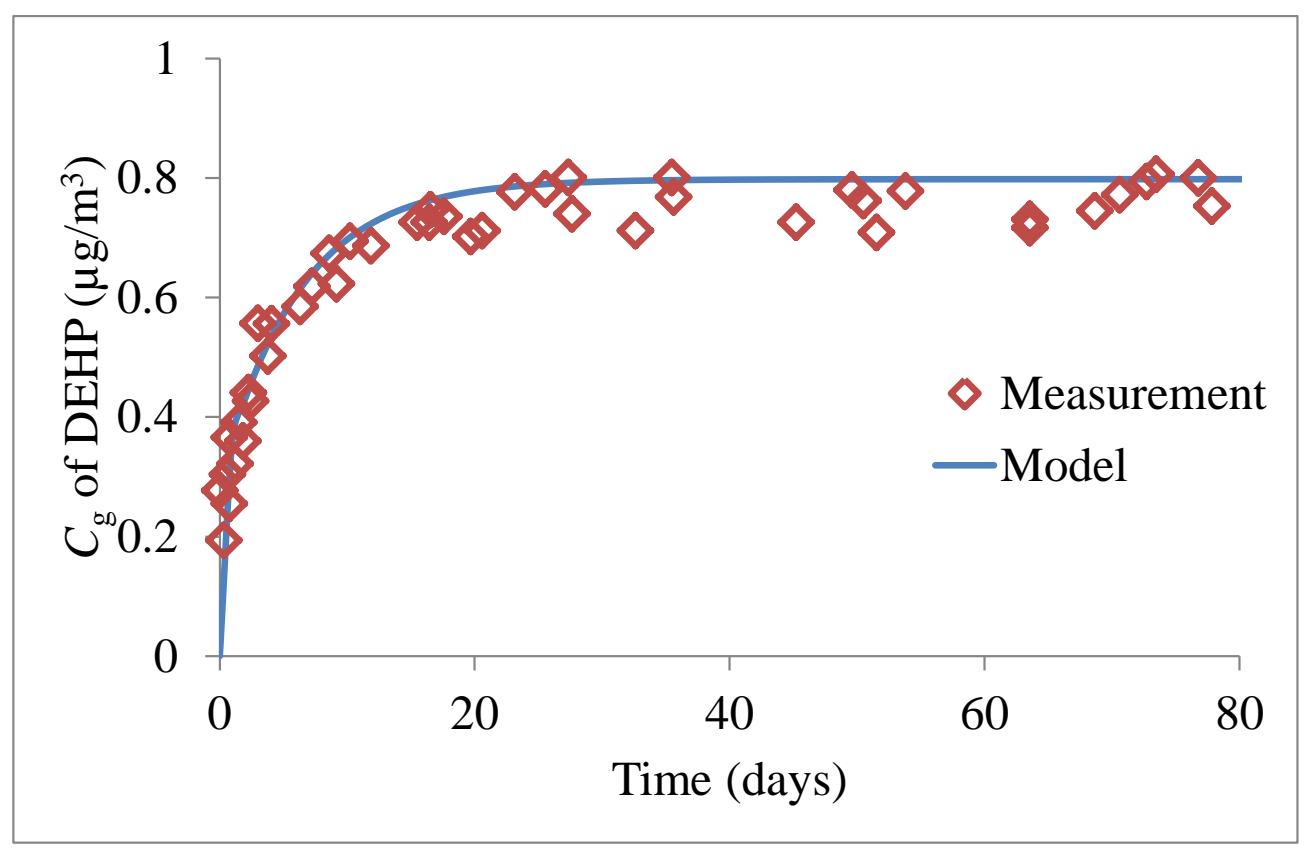

(b) 


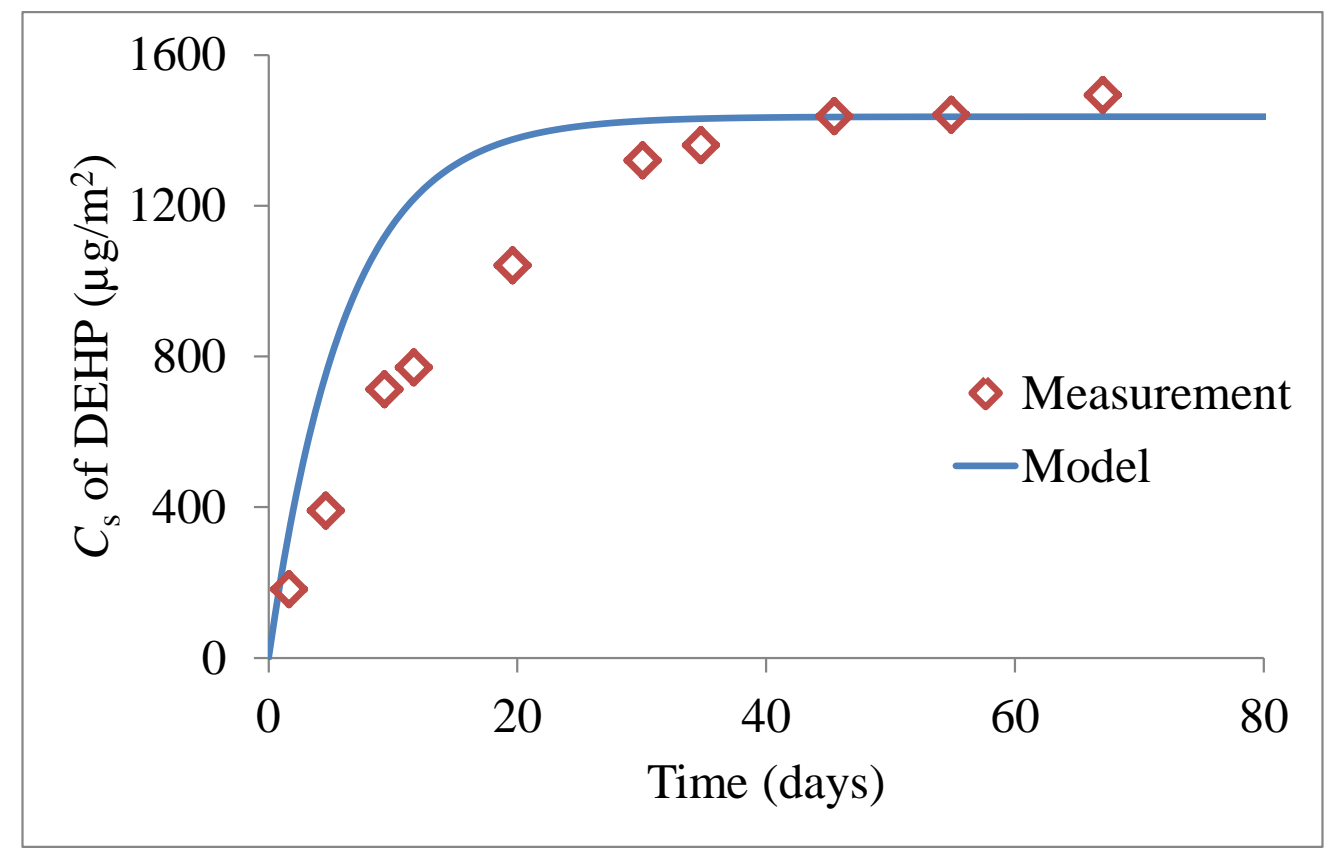

Fig. 3. Hourly average concentration of DEHP in the sandwich-like chamber (a) in the gas phase $\left(C_{\mathrm{g}}\right)$ and $(\mathrm{b})$ on the surface $\left(C_{\mathrm{s}}\right)$ of the chamber. Measured data from [22].

(a) 


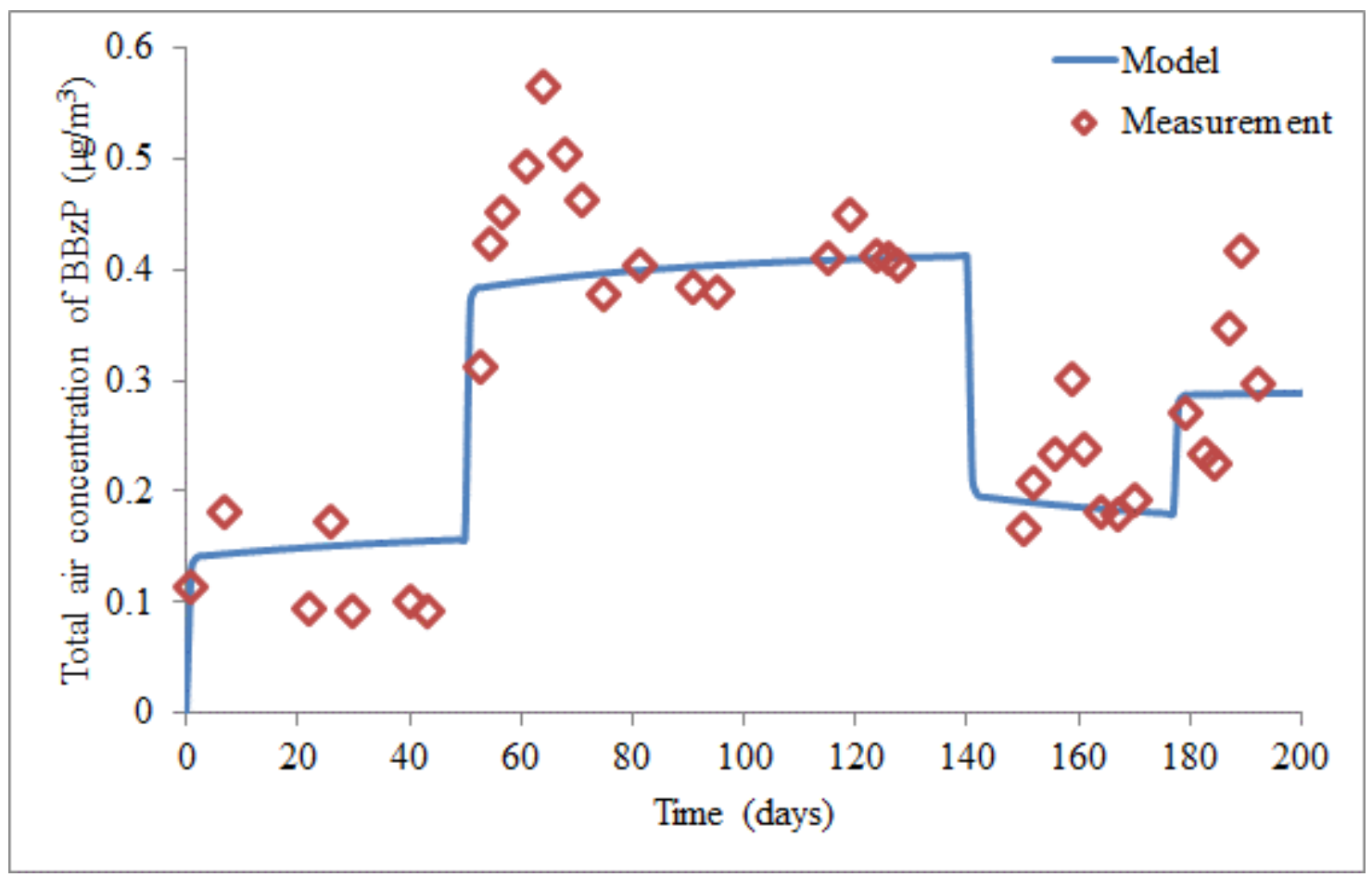

(b)

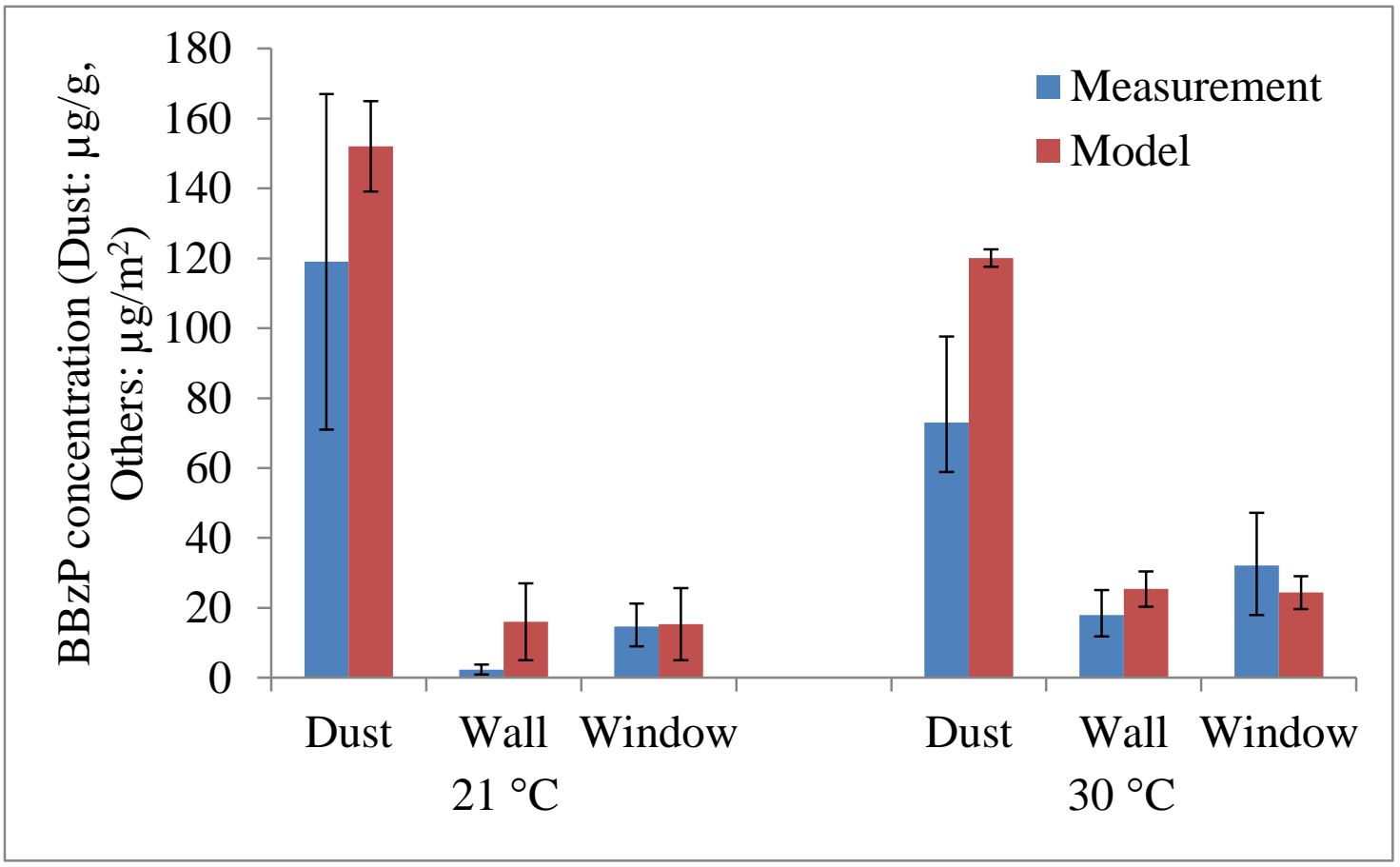


Fig. 4. BBzP concentrations in the test house (a) in the air $\left(C_{\mathrm{g}}+C_{\mathrm{p}}\right)$ and (b) in the settled dust, on the walls, and on the windows. Measured data from [29].

The comparisons of the environmental chamber and the test house results suggest that the model can provide robust estimates of the concentrations of the two phthalates in under both constant and dynamic environmental conditions. The pseudo-first-order reaction rate constants of DEHP and $\mathrm{BBzP}$ are much lower than the AER $\left(25 \mathrm{~h}^{-1}\right.$ in the environmental chamber, and between 0.5 and $0.71 \mathrm{~h}^{-1}$ in the test house), e.g., for the reaction with the hydroxyl radical in the gas phase, the $k_{1 \mathrm{~g}}$ is between $5.1 \times 10^{-3}$ and $1.4 \times 10^{-1} \mathrm{~h}^{-1}$ for DEHP and between $2.6 \times 10^{-3}$ and $7.2 \times 10^{-2} \mathrm{~h}^{-1}$ for BBzP) [16]. Therefore, the reactivity of the two phthalates does not have significant influence on their concentrations indoors. According to a detailed study of SVOC reactivity, reactivity plays an important role in the fate of indoor SVOCs for a number of polycyclic aromatic hydrocarbons (PAHs) and pesticides, such as benzo[a]anthracene, chrysene, benzo[b]fluoranthene, pyrene, diazinon, chlorpyrifos, and aldrin [16].

Over a period of less than 200 days in the test house, the indoor air temperature (between 21 and $30{ }^{\circ} \mathrm{C}$ ) and $\mathrm{RH}$ (between $24.9 \%$ and $40.4 \%$ ) were changed four times. The AER (between 0.5 and $0.71 \mathrm{~h}^{-1}$ ) was changed 3 times. The experimental pattern of the variation in $T, R H, T S P$, and $A E R$ in this study cannot represent real environmental conditions, which have rapider changes. To validate the model in an ordinary room over a long period of time, future studies should measure SVOC concentrations in the gas phase, airborne particles, and settled dust and on indoor surfaces regularly. During the measurement period, indoor environmental factors should be monitored. 


\subsection{Dynamic modeling over a year}

The hourly average concentrations of BBzP under the real environmental conditions of the French office study and considering the case of a newly built room are shown in Figs. 5 and 6 . The modeled concentration profiles considering an existing room are shown in Figs. S6 and S7 in the SI. The distribution of the BBzP concentrations over a year is shown in Table 1. Due to the variation in the environmental factors, the concentrations of $\mathrm{BBzP}$ in all the phases vary by approximately one order of magnitude over a year. In the existing room, the BBzP concentrations vary between 4 and $1.2 \times 10^{3} \mathrm{ng} / \mathrm{m}^{3}$ for $C_{\mathrm{g}}$, between $7.8 \times 10^{-4}$ and $3.1 \times 10^{1} \mathrm{ng} / \mathrm{m}^{3}$ for $C_{\mathrm{p}}$, between 3 and $7.1 \times 10^{2} \mu \mathrm{g} / \mathrm{g}$ for $C_{\mathrm{d}}$, between $5.7 \times 10^{-4}$ and $2.7 \times 10^{1} \mu \mathrm{g} / \mathrm{m}^{2}$ for $C_{\mathrm{s}}$ on the walls, and between $5.7 \times 10^{-4}$ and $2.6 \times 10^{1} \mu \mathrm{g} / \mathrm{m}^{2}$ for $C_{\mathrm{s}}$ on the windows. Student's $t$-tests were performed to test the significance of the difference between the concentrations over the period of the predictions due to the difference in the initial concentrations. The p-values for $C_{\mathrm{g}}(0.51), C_{\mathrm{p}}(0.75)$, and $C_{\mathrm{d}}(0.46)$ are higher than 0.05 , indicating that the initial $\mathrm{BBzP}$ concentrations have nonsignificant influences on the profiles of $C_{\mathrm{g}}, C_{\mathrm{p}}$, and $C_{\mathrm{d}}$ over a year. The p-values for $C_{\mathrm{s}}$ for the walls and windows are less than 0.05 , suggesting that the $C_{\text {s }}$ profiles of the two prediction cases are significantly different (Fig. S8 in the SI). A possible explanation is that BBzP is slowly forming an organic layer on the surface of the walls and windows [6]. Therefore, the initial mass transfer processes for $C_{\mathrm{s}}$, which is associated with the initial concentrations, take longer than those for $C_{\mathrm{g}}$, $C_{\mathrm{p}}$, and $C_{\mathrm{d}}$. Correlation tests show that the values of $C_{\mathrm{g}}$ and $C_{\mathrm{p}}(r=0.86)$ as well as the BBzP concentrations on the two types of sink surfaces $(r>0.999)$ are highly correlated regardless of the initial concentrations used for the prediction (Fig. S9 in the SI). 


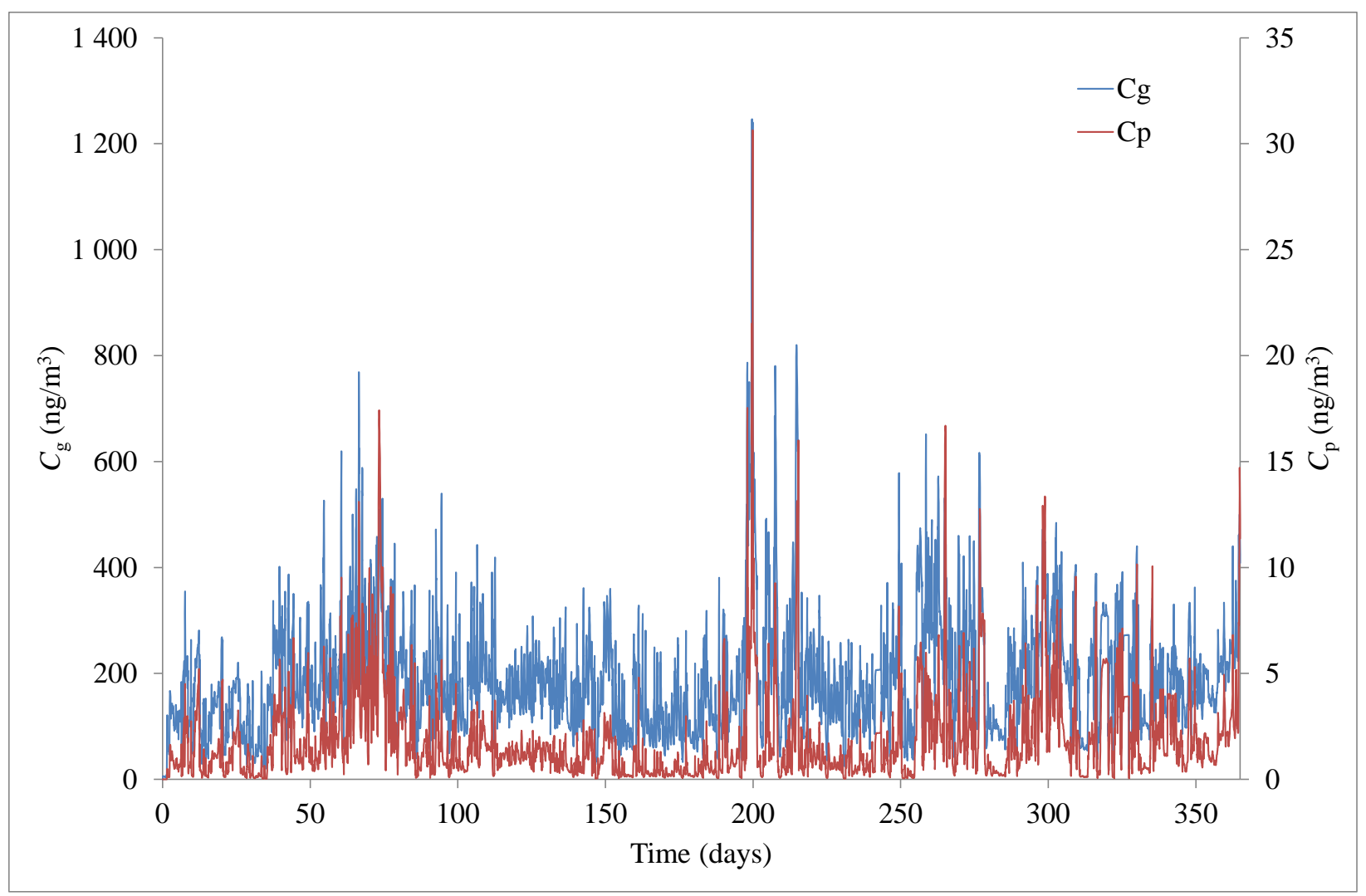

Fig. 5. Predicted hourly average $\mathrm{BBzP}$ concentrations in the gas phase $\left(C_{\mathrm{g}}\right)$ and airborne particles $\left(C_{\mathrm{p}}\right)$ in a newly built room. 


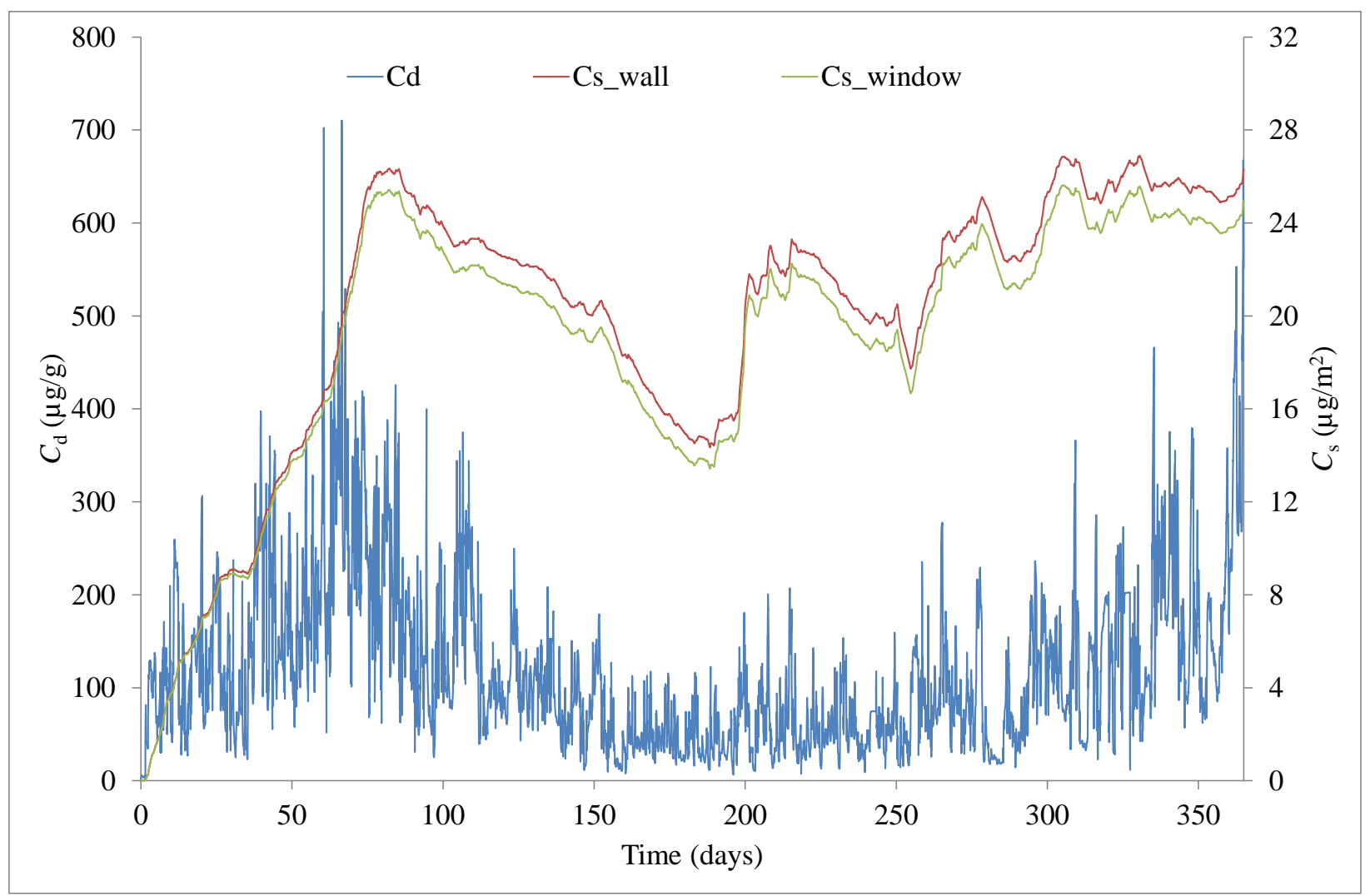

Fig. 6. Predicted hourly average BBzP concentrations in the settled dust $\left(C_{\mathrm{d}}\right)$ and on the surfaces $\left(C_{\mathrm{s}}\right)$ of a newly built room.

Table 1. Distribution of BBzP concentrations over a year

$\begin{array}{lllllll}\text { P5 } & \text { P25 } & \text { P50 } & \text { P75 } & \text { P95 } & \text { Yearly- } & \text { Standard } \\ & & & \text { average } & \text { deviation }\end{array}$

\section{Newly built room}

In the gas phase $\left(\mathrm{ng} / \mathrm{m}^{3}\right)$

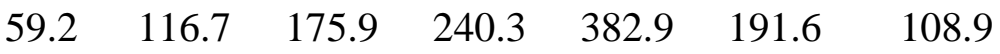




\begin{tabular}{lccccccc}
\hline In airborne particles $\left(\mathrm{ng} / \mathrm{m}^{3}\right)$ & 0.1 & 0.5 & 1.2 & 2.3 & 5.8 & 1.9 & 2.2 \\
In settled dust $(\mu \mathrm{g} / \mathrm{g})$ & 23.2 & 52.2 & 94.3 & 160.3 & 297.8 & 119.1 & 89.2 \\
On walls $\left(\mu \mathrm{g} / \mathrm{m}^{2}\right)$ & 6.2 & 16.8 & 21.9 & 24.6 & 26.2 & 19.9 & 6.1 \\
On windows $\left(\mu \mathrm{g} / \mathrm{m}^{2}\right)$ & 6.1 & 15.9 & 20.9 & 23.5 & 25.2 & 19.0 & 5.8 \\
& & & & & & &
\end{tabular}

\section{Existing room}

$\begin{array}{llllllll}\text { In the gas phase }\left(\mathrm{ng} / \mathrm{m}^{3}\right) & 59.8 & 117.5 & 177.2 & 241.5 & 383.4 & 192.7 & 109.0\end{array}$

$\begin{array}{llllllll}\text { In airborne particles }\left(\mathrm{ng} / \mathrm{m}^{3}\right) & 0.1 & 0.5 & 1.2 & 2.3 & 5.8 & 1.9 & 2.2\end{array}$

$\begin{array}{llllllll}\text { In settled dust }(\mu \mathrm{g} / \mathrm{g}) & 23.3 & 52.4 & 94.8 & 162.0 & 299.5 & 120.0 & 90.0\end{array}$

$\begin{array}{llllllll}\text { On walls }\left(\mu \mathrm{g} / \mathrm{m}^{2}\right) & 11.9 & 17.7 & 22.1 & 24.9 & 26.6 & 20.9 & 4.6\end{array}$

$\begin{array}{llllllll}\text { On windows }\left(\mu \mathrm{g} / \mathrm{m}^{2}\right) & 11.4 & 16.8 & 21.0 & 23.6 & 25.4 & 19.8 & 4.4\end{array}$

The environmental factors have combined effects on the mass transfer parameters (Fig. S10 in the SI) and concentrations (Fig. S11 in the SI). When the temperature increases, all concentrations increase because of the increasing $y_{0}[8,23]$ and mass transfer coefficients $[26,33]$ and the decreasing partition coefficients [34-36]. When the RH increases, $C_{\mathrm{p}}$ and $C_{\mathrm{d}}$ decrease because of the decreasing $K_{\mathrm{p}}$ and $K_{\mathrm{d}}$ values [37,38]. The substrate of indoor settled dust includes soil, settled particles, human and animal dander, cloth fibers, and fungal material [39-41] and varies widely among indoor environments [42]. The impact of RH on $K_{\mathrm{d}}$ was available in the literature only for soil $[18,38]$. No equation is available in the literature to quantitatively address the influence of RH 
on $K_{\mathrm{s}}$. Therefore, this influence is not included in the current model. When the $\mathrm{PM}_{10}$ concentration increases, all concentrations increase because of the increasing mass transfer coefficients $[43,44]$. When the AER increases, all the concentrations decrease if other environmental factors remain unchanged. The contributions of the environmental factors to the variance in the SVOC concentrations were estimated using Eq. (6). To reduce the influence of the variance associated with the initial conditions and the initial mass transfer process, the analysis was carried out only for case 2 (Fig. 7). More than $52 \%$ of the variances in all the phases $\left(60 \%\right.$ for $C_{\mathrm{g}}, 82 \%$ for $C_{\mathrm{p}}, 52 \%$ for $C_{\mathrm{d}}, 65 \%$ for $C_{\mathrm{s}}$ on the walls, and $64 \%$ for $C_{\mathrm{s}}$ on the windows) are associated with the covariances of the environmental factors, which cannot be separated. In addition, more than $16 \%$ of the variances in all the phases $\left(27 \%\right.$ for $C_{\mathrm{g}}, 16 \%$ for $C_{\mathrm{p}}, 36 \%$ for $C_{\mathrm{d}}, 19 \%$ for $C_{\mathrm{s}}$ on the walls, and $20 \%$ for $C_{\mathrm{s}}$ on the windows) are associated with the variance in the AER. The variance in indoor temperatures contributes to $9 \%$ of the variance in $C_{\mathrm{g}}$. The variance in the $\mathrm{RH}$ contributes to $7 \%$ of the variance in $C_{\mathrm{d}}$. The variance in the indoor $\mathrm{PM}_{10}$ concentrations contributes to $10 \%$ of the variance in $C_{\mathrm{s}}$ for the walls and windows. Due to the variations in the environmental factors, a seasonal difference was observed in all concentrations. The highest 3-month average value of $C_{\mathrm{g}}$ $\left(222 \mathrm{ng} / \mathrm{m}^{3}\right)$ appeared in the $3^{\text {rd }}$ quarter of the year (July 1-September 30, 2014), probably due to high indoor air temperatures and $\mathrm{PM}_{10}$ concentration, which increase the values of $y_{0}$ and the mass transfer coefficient for the source surfaces. The highest 3-month average values of $C_{\mathrm{p}}\left(2.4 \mathrm{ng} / \mathrm{m}^{3}\right)$ and $C_{\mathrm{s}}\left(25 \mu \mathrm{g} / \mathrm{m}^{2}\right.$ for the walls and $24 \mu \mathrm{g} / \mathrm{m}^{2}$ for the windows) appeared in the $4^{\text {th }}$ quarter of the year (October 1-December 31, 2014), probably due to low AERs and low indoor air temperatures, which increase the particle/gas and sink/gas partition coefficients. The highest 3-month average value of $C_{\mathrm{d}}\left(181 \mathrm{ng} / \mathrm{m}^{3}\right)$ appeared in the $1^{\text {st }}$ quarter of the year (January 1-March 31, 2014), 
probably due to the low $\mathrm{RH}$ and temperatures in indoor air, which increase the dust/gas partition coefficient.

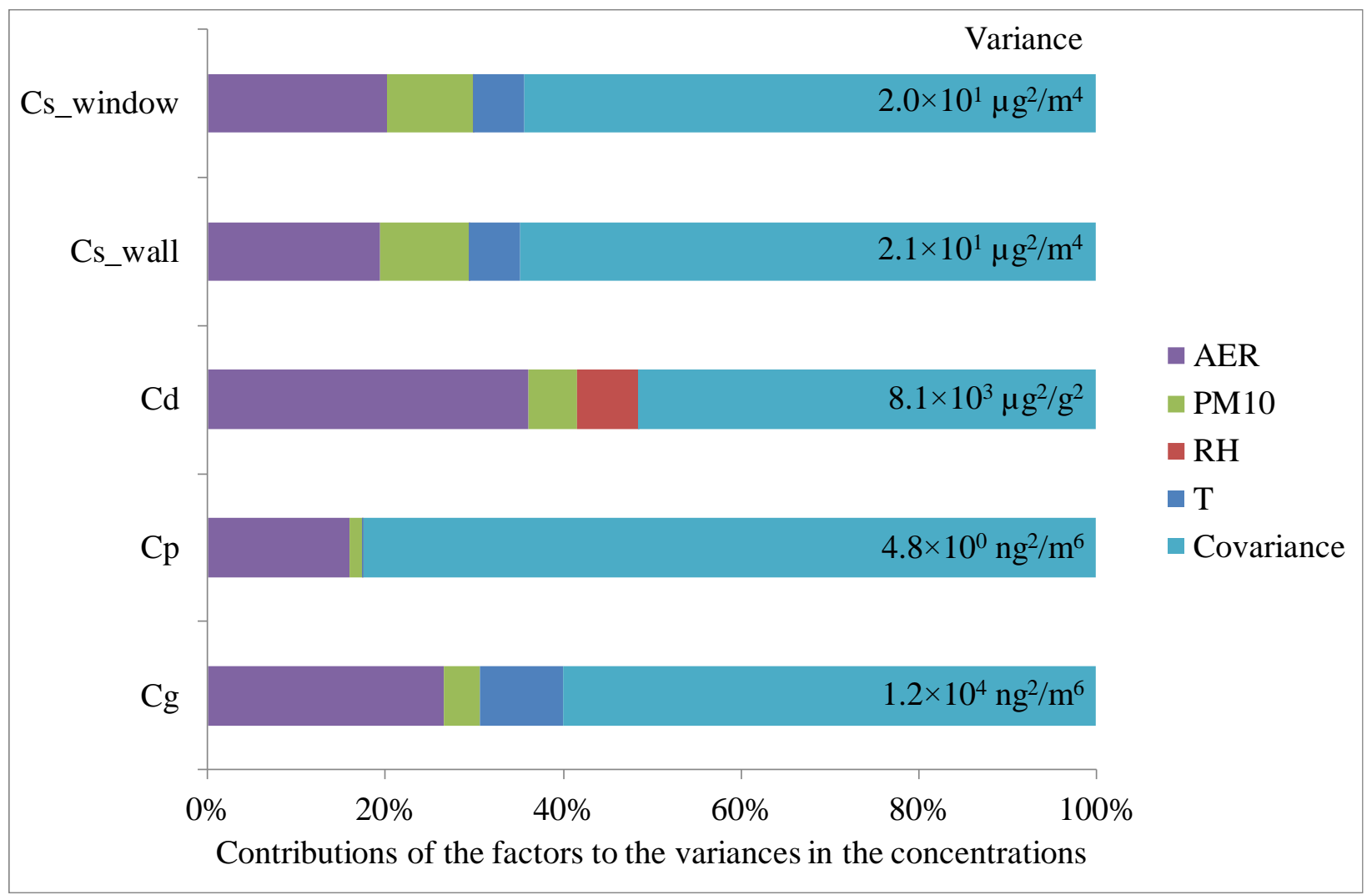

Fig. 7. Contributions of the environmental factors to the variances in $\mathrm{BBzP}$ concentrations (existing room)

\subsection{Perspectives for improving the model}

The dynamic model developed in the present study characterizes the SVOC mass transfer mechanisms (emission and partition) and reactivity in indoor environments. The influence of 
indoor environmental factors (temperature, RH, AER, and concentration of total suspended particles) on the mass transfer parameters were taken into account in each time step of the calculation. The model was validated using measurement results of two studies in the literature. Due to the lack of studies on SVOC mass transfer in indoor environments, the validations were carried out for DEHP only in the gas phase in an environmental chamber under constant environmental conditions and for BBzP in the air, settled dust, walls and windows in a test house under regulated environmental conditions. Both the validation and application of the model focused on phthalates due to the lack of relevant data on other compounds. The lack of data on the input parameters of the model is a crucial limitation to the application of the model to other SVOCs. To validate the full prediction capacity of the model, the concentrations of a number of SVOCs in all the phases indoors and outdoors need to be measured over a long period of time in a real environment. The environmental factors should be monitored during the period of SVOC measurements. Moreover, the model can be improved in the following aspects.

(1) The model is currently developed for an unoccupied room. The influence of human activities, e.g., cooking and cleaning, on indoor environmental factors and SVOC concentrations has not been considered. Human activities may lead to the emission of particles and chemical compounds, resuspension of settle dust, and dust entry and removal.

(2) The model does not consider SVOC emissions from intermittent sources. These sources include, e.g., the emissions of polyaromatic hydrocarbons due to cooking, the spray of synthetic musks and pesticides, and other punctual usage of products containing SVOCs.

(3) The model considers indoor impermeable sink surfaces and does not take into account porous sink surfaces. Porous surfaces may lead to significant SVOC reservoirs and extend SVOC persistence in an indoor environment. 
(4) The model considers that the transport efficiency of SVOCs between indoor and outdoor environments equals one. In fact, this value may differ depending on the system of ventilation. The model requires the concentration of total suspended particles as an input. This value currently comes from measurements or the output of other models. The current model does not predict the indoor concentration of the total suspended particles, regardless of their origins from indoor or outdoor sources.

(5) The model predicts the average concentration of SVOC in airborne particles and settled dust for $\mathrm{PM}_{10}$. Recent studies have shown some effects of particle size distribution and age on indoor SVOC concentrations in different phases [45]. These effects should be considered for further improvement of the model. For this purpose, the size distribution of indoor airborne particles and its changes over time need to be defined based on measurements or modeling approaches. Moreover, future studies should address the indoor particle size distribution and particle-related parameters, such as the partition coefficient, deposition velocity, and resuspension rate, in terms of the size effect.

\section{CONCLUSIONS}

A long-term dynamic model was developed to predict the concentrations of SVOCs in indoor environments. The model characterizes the emission of SVOCs from multiple source surfaces and the sorption of SVOCs onto multiple sink surfaces for the prediction of the SVOC concentrations in the gas phase, airborne particles, and settled dust and on each sink surface. The model takes into account the mass transfer mechanisms of SVOCs in an indoor environment, the possible contribution of the outdoor SVOC concentration when the transfer efficiency is assumed to be one, 
and the reactions of SVOCs with hydroxyl radicals, nitrate radicals, and ozone. The impacts of indoor air temperature, $\mathrm{RH}$, the concentration of the total suspended particles, and the AER on the mass transfer parameters and SVOC concentrations are calculated quantitatively in each time step of the calculation. Therefore, the model can be applied to both environmental chambers under regulated environmental conditions and unoccupied rooms under real environmental conditions.

\section{ACKNOWLEDGMENTS}

The research leading to these results has received funding from the People Programme (Marie Curie Actions) of the European Union's Seventh Framework Programme (FP7/2007-2013) under

REA grant agreement n. PCOFUND-GA-2013-609102, through the PRESTIGE program coordinated by Campus France (PRESTIGE-2015-3-0016).

\section{REFERENCES}

[1] C.J. Weschler, W.W. Nazaroff, Semivolatile organic compounds in indoor environments, Atmos. Environ. (2008). doi:10.1016/j.atmosenv.2008.09.052.

[2] C. Liu, Y. Zhang, C.J. Weschler, Exposure to SVOCs from inhaled particles: the impact of desorption, Environ. Sci. Technol. 51 (2017) 6220-6228. doi:10.1021/acs.est.6b05864.

[3] C.J. Weschler, G. Bekö, H.M. Koch, T. Salthammer, T. Schripp, J. Toftum, G. Clausen, Transdermal uptake of diethyl phthalate and di(n-butyl) phthalate directly from air: Experimental verification, Environ. Health Perspect. 123 (2015) 928-934. 
doi:10.1289/ehp.1409151.

[4] S. Tajima, A. Araki, T. Kawai, T. Tsuboi, Y. Ait Bamai, E. Yoshioka, A. Kanazawa, S. Cong, R. Kishi, Detection and intake assessment of organophosphate flame retardants in house dust in Japanese dwellings, Sci. Total Environ. 478 (2014) 190-199. doi:10.1016/j.scitotenv.2013.12.121.

[5] Y. Wu, C.M.A. Eichler, W. Leng, S.S. Cox, L.C. Marr, J.C. Little, Adsorption of Phthalates on Impervious Indoor Surfaces, Environ. Sci. Technol. 51 (2017) 2907-2913. doi:10.1021/acs.est.6b05853.

[6] C.J. Weschler, W.W. Nazaroff, Growth of organic films on indoor surfaces., Indoor Air. 27 (2017) 1101-1112. doi:10.1111/ina.12396.

[7] G.C. Morrison, H. V. Andersen, L. Gunnarsen, D. Varol, E. Uhde, B. Kolarik, Partitioning of PCBs from air to clothing materials in a Danish apartment., Indoor Air. 28 (2018) 188197. doi:10.1111/ina.12411.

[8] J. Cao, X. Zhang, J.C. Little, Y. Zhang, A SPME-based method for rapidly and accurately measuring the characteristic parameter for DEHP emitted from PVC floorings, Indoor Air. 27 (2017) 417-426. doi:10.1111/ina.12312.

[9] D.H. Bennett, E.J. Furtaw, Fugacity-Based Indoor Residential Pesticide Fate Model, Environ. Sci. Technol. (2004). doi:10.1021/es034287m.

[10] H.M. Shin, T.E. McKone, D.H. Bennett, Intake fraction for the indoor environment: A tool for prioritizing indoor chemical sources, Environ. Sci. Technol. (2012). 
doi:10.1021/es3018286.

[11] X. Zhang, M.L. Diamond, C. Ibarra, S. Harrad, Multimedia modeling of polybrominated diphenyl ether emissions and fate indoors, Environ. Sci. Technol. 43 (2009) 2845-2850. doi:10.1021/es802172a.

[12] Y. Xu, J.C. Little, Predicting emissions of SVOCs from polymeric materials and their interaction with airborne particles, Environ. Sci. Technol. 40 (2006) 456-461. doi:10.1021/es051517j.

[13] Y. Xu, E.A.C. Hubal, P.A. Clausen, J.C. Little, Predicting residential exposure to phthalate plasticizer emitted from vinyl flooring: A mechanistic analysis, Environ. Sci. Technol. 43 (2009) 2374-2380. doi:10.1021/es801354f.

[14] C. Liu, B. Zhao, Y. Zhang, The influence of aerosol dynamics on indoor exposure to airborne DEHP, Atmos. Environ. $44 \quad$ (2010) 1952-1959. doi:10.1016/j.atmosenv.2010.03.002.

[15] S. Shi, B. Zhao, Modeled exposure assessment via inhalation and dermal pathways to airborne semivolatile organic compounds (SVOCs) in residences, Environ. Sci. Technol. 48 (2014) 5691-5699. doi:10.1021/es500235q.

[16] W. Wei, C. Mandin, O. Ramalho, Reactivity of semivolatile organic compounds with hydroxyl radicals, nitrate radicals, and ozone in indoor air, Int. J. Chem. Kinet. 49 (2017) $506-521$.

[17] W. Wei, C. Mandin, O. Blanchard, F. Mercier, M. Pelletier, B. Le Bot, P. Glorennec, O. 
Ramalho, Predicting the gas-phase concentration of semi-volatile organic compounds from airborne particles: Application to a French nationwide survey, Sci. Total Environ. 576 (2017) 319-325. doi:10.1016/j.scitotenv.2016.10.074.

[18] W. Wei, C. Mandin, O. Ramalho, Influence of indoor environmental factors on mass transfer parameters and concentrations of semi-volatile organic compounds., Chemosphere. 195 (2018) 223-235. doi:10.1016/j.chemosphere.2017.12.072.

[19] Y. Liang, X. Liu, M.R. Allen, Measuring and modeling surface sorption dynamics of organophosphate flame retardants on impervious surfaces, Chemosphere. 193 (2018) 754762. doi:10.1016/j.chemosphere.2017.11.080.

[20] I. Liagkouridis, B. Lazarov, G. Giovanoulis, I.T. Cousins, Mass transfer of an organophosphate flame retardant between product source and dust in direct contact, Emerg. Contam. 3 (2017). doi:https://doi.org/10.1016/j.emcon.2017.09.002.

[21] V. Sukiene, N. von Goetz, A.C. Gerecke, M.I. Bakker, C.J.E. Delmaar, K. Hungerbuehler, Direct and air-mediated transfer of labeled SVOCs from indoor sources to dust, Environ. Sci. Technol. 51 (2017) 3269-3277. doi:10.1021/acs.est.6b06051.

[22] Y. Xu, Z. Liu, J. Park, P.A. Clausen, J.L. Benning, J.C. Little, Measuring and predicting the emission rate of phthalate plasticizer from vinyl flooring in a specially-designed chamber, Environ. Sci. Technol. 46 (2012) 12534-12541. doi:10.1021/es302319m.

[23] Y. Liang, Y. Xu, Emission of phthalates and phthalate alternatives from vinyl flooring and crib mattress covers: The influence of temperature, Environ. Sci. Technol. 48 (2014) 14228-14237. doi:10.1021/es504801x. 
[24] J. Guo, K. Lin, J. Deng, X. Fu, Z. Xu, Polybrominated diphenyl ethers in indoor air during waste TV recycling process, J. Hazard. Mater. 283 (2015) 439-446. doi:10.1016/j.jhazmat.2014.09.044.

[25] I. Saito, A. Onuki, H. Seto, Indoor organophosphate and polybrominated flame retardants in Tokyo, Indoor Air. 17 (2007) 28-36. doi:10.1111/j.1600-0668.2006.00442.x.

[26] B. Deng, C.N. Kim, An analytical model for VOCs emission from dry building materials, Atmos. Environ. 38 (2004) 1173-1180. doi:10.1016/j.atmosenv.2003.11.009.

[27] S. Shi, B. Zhao, Estimating indoor semi-volatile organic compounds (SVOCs) associated with settled dust by an integrated kinetic model accounting for aerosol dynamics, Atmos. Environ. 107 (2015) 52-61. doi:10.1016/j.atmosenv.2015.01.076.

[28] W. Wei, C. Mandin, O. Blanchard, F. Mercier, M. Pelletier, B. Le Bot, P. Glorennec, O. Ramalho, Distributions of the particle/gas and dust/gas partition coefficients for seventytwo semi-volatile organic compounds in indoor environment, Chemosphere. 153 (2016) 212-219. doi:10.1016/j.chemosphere.2016.03.007.

[29] C. Bi, Y. Liang, Y. Xu, Fate and Transport of Phthalates in Indoor Environments and the Influence of Temperature: A Case Study in a Test House, Environ. Sci. Technol. 49 (2015) 9674-9681. doi:10.1021/acs.est.5b02787.

[30] O. Ramalho, R. Ouaret, A. Ionescu, E. Le Ponner, Y. Candau, Real time monitoring of indoor air quality in offices - source contributions and forecasting model, 2016.

[31] R. Ouaret, A. Ionescu, O. Ramalho, Y. Candau, Indoor air pollutant sources using blind 
source separation methods, in: Proc. 25th Eur. Symp. Artif. Neural Networks, Comput. Intell. Mach. Learn., 2017: pp. 239-244.

[32] O. Ramalho, C. Mandin, J. Ribéron, G. Wyart, Air stuffiness and air exchange rate in French schools and day-care centres, Int. J. Vent. (2013). doi:10.1080/14733315.2013.11684013.

[33] T. Holmgren, L. Persson, P.L. Andersson, P. Haglund, A generic emission model to predict release of organic substances from materials in consumer goods, Sci. Total Environ. 437 (2012) 306-314. doi:10.1016/j.scitotenv.2012.08.020.

[34] H.P.H. Arp, K.-U. Goss, R.P. Schwarzenbach, Evaluation of a predictive model for air/surface adsorption equilibrium constants and enthalpies., Environ. Toxicol. Chem. 25 (2006) 45-51. doi:10.1897/05-291r.1.

[35] K.-U. Goss, The Air/Surface Adsorption Equilibrium of Organic Compounds Under Ambient Conditions, Crit. Rev. Environ. Sci. Technol. 34 (2004) 339-389. doi:10.1080/10643380490443263.

[36] W. Wei, C. Mandin, O. Blanchard, F. Mercier, M. Pelletier, B. Le Bot, P. Glorennec, O. Ramalho, Temperature dependence of the particle/gas partition coefficient: An application to predict indoor gas-phase concentrations of semi-volatile organic compounds, Sci. Total Environ. 563-564 (2016) 506-512. doi:10.1016/j.scitotenv.2016.04.106.

[37] M. Jang, R.M. Kamens, A thermodynamic approach for modeling partitioning of semivolatile organic compounds on atmospheric particulate matter: Humidity effects, Environ. Sci. Technol. 32 (1998) 1237-1243. doi:10.1021/es970773w. 
[38] M. Hippelein, M.S. McLachlan, Soil/Air Partitioning of Semivolatile Organic Compounds. 2. Influence of Temperature and Relative Humidity, Environ. Sci. Technol. 34 (2000) 35213526. doi:10.1021/es991421n.

[39] Z. Cao, G. Yu, Y. Chen, C. Liu, K. Liu, T. Zhang, B. Wang, S. Deng, J. Huang, Mechanisms influencing the BFR distribution patterns in office dust and implications for estimating human exposure, J. Hazard. Mater. 252-253 (2013) 11-18. doi:10.1016/j.jhazmat.2013.02.043.

[40] P.J. Lioy, N.C.G. Freeman, J.R. Millette, Dust: A metric for use in residential and building exposure assessment and source characterization, Environ. Health Perspect. 110 (2002) 969-983. doi:10.1289/ehp.02110969.

[41] R.M. Maertens, J. Bailey, P.A. White, The mutagenic hazards of settled house dust: A review, Mutat. Res. - Rev. Mutat. Res. 567 (2004) 401-425. doi:10.1016/j.mrrev.2004.08.004.

[42] P.E. Rasmussen, K.S. Subramanian, B.J. Jessiman, A multi-element profile of house dust in relation to exterior dust and soils in the city of Ottawa, Canada, Sci. Total Environ. 267 (2001) 125-140. doi:10.1016/S0048-9697(00)00775-0.

[43] C. Liu, G.C. Morrison, Y. Zhang, Role of aerosols in enhancing SVOC flux between air and indoor surfaces and its influence on exposure, Atmos. Environ. 55 (2012) 347-356. doi:10.1016/j.atmosenv.2012.03.030.

[44] C. Liu, Y. Zhang, J.L. Benning, J.C. Little, The effect of ventilation on indoor exposure to semivolatile organic compounds, Indoor Air. 25 (2015) 285-296. doi:10.1111/ina.12139. 
[45] J. Cao, J. Mo, Z. Sun, Y. Zhang, Indoor particle age, a new concept for improving the accuracy of estimating indoor airborne SVOC concentrations, and applications, Build. Environ. 136 (2018) 88-97. doi:10.1016/j.buildenv.2018.03.028. 